\title{
Experimental Research on $\mathrm{NH}_{3}$-SCR Performance of $\mathrm{Mn}-\mathrm{Ce} / \mathrm{TiO}{ }_{2}$ Catalyst
}

\author{
Guoyou Xu, Yating Wang, Yue Yang, Yang Fu, Xiang Gou ${ }^{a}$, Jinxiang Wu
}

School of Energy and Environmental Engineering, Hebei University of Technology, Tianjin 300401, China

${ }^{a}$ Corresponding author email: gouxiang@sina.com

Keywords: $\mathrm{SCR} ; \mathrm{NH}_{3}-\mathrm{NO}$ ratio; $\mathrm{Mn} ; \mathrm{Ce} ; \mathrm{CO}_{2}$ atmosphere

\begin{abstract}
NO}_{\mathrm{X}}$ pollutions affect our social manufacture and human being living, which has caused the extensive attention. $\mathrm{NH}_{3}$-SCR (selective catalytic reduction) has been largely studied to reduce $\mathrm{NO}_{\mathrm{X}}$ pollution. Most people focus on catalysts under $\mathrm{N}_{2}$ and inert gases atmosphere, while few people research on the study of $\mathrm{CO}_{2}$ as balance gas on oxy-fuel combustion condition. In this work, $\mathrm{TiO}_{2}$ served as $\mathrm{Mn}$ - and Ce- support. The experiments were performed under $\mathrm{CO}_{2}$ and $\mathrm{N}_{2}$ atmosphere respectively. The results showed that $\mathrm{CO}_{2}$ could inhibit NO conversion. The molar ratio of $\mathrm{NH}_{3}$ to $\mathrm{NO}$ at 1.2:1 obtained a better $\mathrm{NO}$ conversion with $\mathrm{Mn}-\mathrm{Ce} / \mathrm{TiO}_{2}$ catalyst.
\end{abstract}

\section{Introduction}

With the fast increasing economy, the environment problems also become serious than before[1]. NOx is one of the most serious pollutants, which has a bad impact on human being living environment. Not only has the environment been damaged by NOx, but also has a badly harm to human health. Urban smog, acid rain, ozone-depleting are all caused by excessive NOx emissions[2], which needs to be limited to a certain level as soon as possible that does not put the environment in danger. As power plants are mainly responsible for the excessive NOx emissions, appropriate measures should be taken to reduce them. SCR or $\mathrm{NH}_{3}$-SCR (Selective catalytic reduction of $\mathrm{NOx}$ with $\mathrm{NH}_{3}$ ) is the most popular method to solve excessive $\mathrm{NOx}$ emissions problem[3][4].

Most people focus on catalysts under $\mathrm{N}_{2}$ and inert gases atmosphere, $\mathrm{Yu}$ et al. [5] studyed on Mn-Ce-CO/TiO $\left(\mathrm{N}_{2}\right.$ as balanced gas) and have found $\mathrm{TiO}_{2}$ supports Mn-Ce-Co metal had pretty good performance of DeNOx. However, oxy-fuel combustion will be the future combustion method, which would generate almost $\mathrm{CO}_{2}$ and none $\mathrm{N}_{2}$ in the exhausted gas. With this trend, it is important to research on $\mathrm{CO}_{2}$ atmosphere. But, little work of $\mathrm{NH}_{3}$-SCR have been done under $\mathrm{CO}_{2}$ atmosphere. Gou et al. [6] have worked on Mn-Ce/AC (Activated Carbon) under $\mathrm{CO}_{2}$ atmosphere, and found that the NO conversion inhibition effect of $\mathrm{CO}_{2}$ could be reduced by Mn metal and increased by Ce metal. Wu et al. [7] have worked on the ratio of $\mathrm{NH}_{3}$ to $\mathrm{NO}$ at the temperature range of $100-220^{\circ} \mathrm{C}$ and found that $1.05: 1$ would be a better choice to improve NO conversation. In this work, under simulated flue gas (both $\mathrm{N}_{2}$ and $\mathrm{CO}_{2}$ atmosphere) condition, Mn-Ce/TiO $\mathrm{T}_{2}$ catalysts were studied, which were prepared by impregnation method. While altering $\mathrm{NH}_{3}-\mathrm{NO}$ ratio at $250^{\circ} \mathrm{C}$, 1.2:1 could be a better $\mathrm{NH}_{3}-\mathrm{NO}$ ratio.

\section{Reductant and reaction}

Generally, $\mathrm{NH}_{3}, \mathrm{CO}\left(\mathrm{NH}_{2}\right)_{2}, \mathrm{CH}_{3} \mathrm{CH}_{2} \mathrm{OH}, \mathrm{C}_{3} \mathrm{H}_{6}$, and $\mathrm{H}_{2}$ have been chosen as the SCR reductants. Among them, $\mathrm{NH}_{3}$ is normally used in industry. In Figure 1. SCR reaction mechanism was showed. The main chemical reaction equations are as following:

(1) Under rich $\mathrm{O}_{2}$ condition.

$4 \mathrm{NH}_{3}+4 \mathrm{NO}+\mathrm{O}_{2} \rightarrow 4 \mathrm{~N}_{2}+6 \mathrm{H}_{2} \mathrm{O}$

$4 \mathrm{NH}_{3}+2 \mathrm{NO}_{2}+\mathrm{O}_{2} \rightarrow 3 \mathrm{~N}_{2}+6 \mathrm{H}_{2} \mathrm{O}$

(2)Under absence of $\mathrm{O}_{2}$ condition.

$8 \mathrm{NH}_{3}+6 \mathrm{NO}_{2} \rightarrow 7 \mathrm{~N}_{2}+12 \mathrm{H}_{2} \mathrm{O}$ 


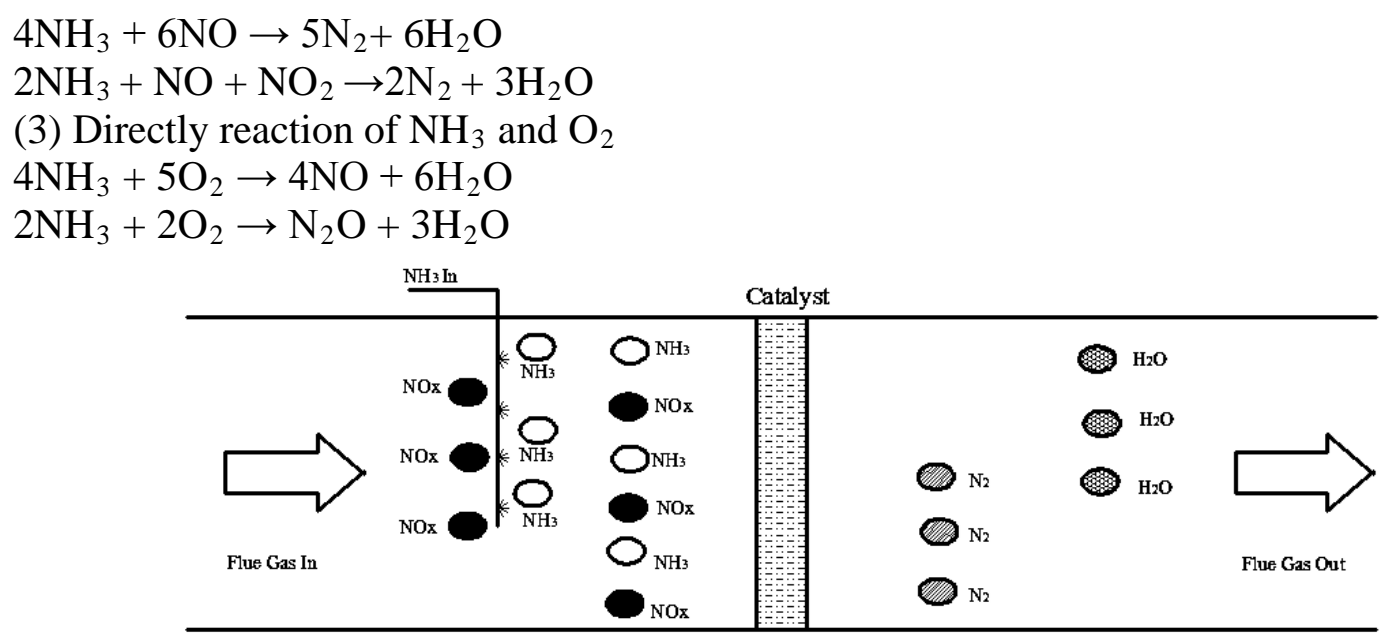

Figure $1 . \mathrm{NH}_{3}$-SCR reaction mechanism

\section{Catalysts Preparation}

In this work, impregnation method was used to prepare $\mathrm{Mn}-\mathrm{Ce} / \mathrm{TiO}{ }_{2} \mathrm{SCR}$ catalysts. $\mathrm{TiO}_{2}$ was chosen as catalyst support. About $50 \mathrm{ml}$ de-ionized water was needed to dissolve $\mathrm{Ce}\left(\mathrm{NO}_{3}\right)_{3} \cdot 6 \mathrm{H}_{2} \mathrm{O}$ and $\mathrm{Mn}\left(\mathrm{NO}_{3}\right)_{2}$, then $\mathrm{TiO}_{2}$ powder was mixed with $\mathrm{Ce}\left(\mathrm{NO}_{3}\right)_{3}$ and $\mathrm{Mn}\left(\mathrm{NO}_{3}\right)_{2}$ solution. The solution was stirred on an automatic mixer about a hour, to insure $\mathrm{Mn}$ - and $\mathrm{Ce}$ - to be adhered on $\mathrm{TiO}_{2}$ surface. The solution was put in the $90^{\circ} \mathrm{C}$ thermostatic waterbath till only solid left.

$\mathrm{Mn}-\mathrm{Ce} / \mathrm{TiO}_{2}$ catalyst solid was dried by a muffle furnace for 12 hours after constant warm water bath, then the dried catalyst was grinded to 40-100 mesh. The catalyst shoud be put in fixed-bed to be calcined at $500{ }^{\circ} \mathrm{C}$ for $2 \mathrm{~h}$ and then cooled down to indoor temperature in $\mathrm{N}_{2}$ atmosphere.

\section{Experimental System}

This experiment was carried out in the fixed-bed reactor. Catalyst would be put into fixed-bed reactor before simulated gases $\left(\mathrm{N}_{2} / \mathrm{CO}_{2}, \mathrm{O}_{2}\right.$ and $\left.\mathrm{NH}_{3}\right)$ was introduced into the fixed-bed reactor. Figure 2 shows the $\mathrm{NH}_{3}$-SCR experiment system.

The feed gas was composed of a certain ratio of $\mathrm{N}_{2} / \mathrm{CO}_{2}, \mathrm{O}_{2}$ and NO, which were controlled by mass flow meters. The simulated gases were mixed in the gas mixer. In the composition gas, $\mathrm{N}_{2} / \mathrm{CO}_{2}$ was used as balanced gas. The simulated gases were introduced into fixed-bed reactor that was controlled by the temperature controller. In the fixed-bed reactor, DeNOx reactions would proceed. Testo 350 XL Flue Gas Analyzer was used to analyse the NO concentration, and at the same time the computer could record the experiment data. The exhausted flue gas shoud be collected in case of poison the experimenters.

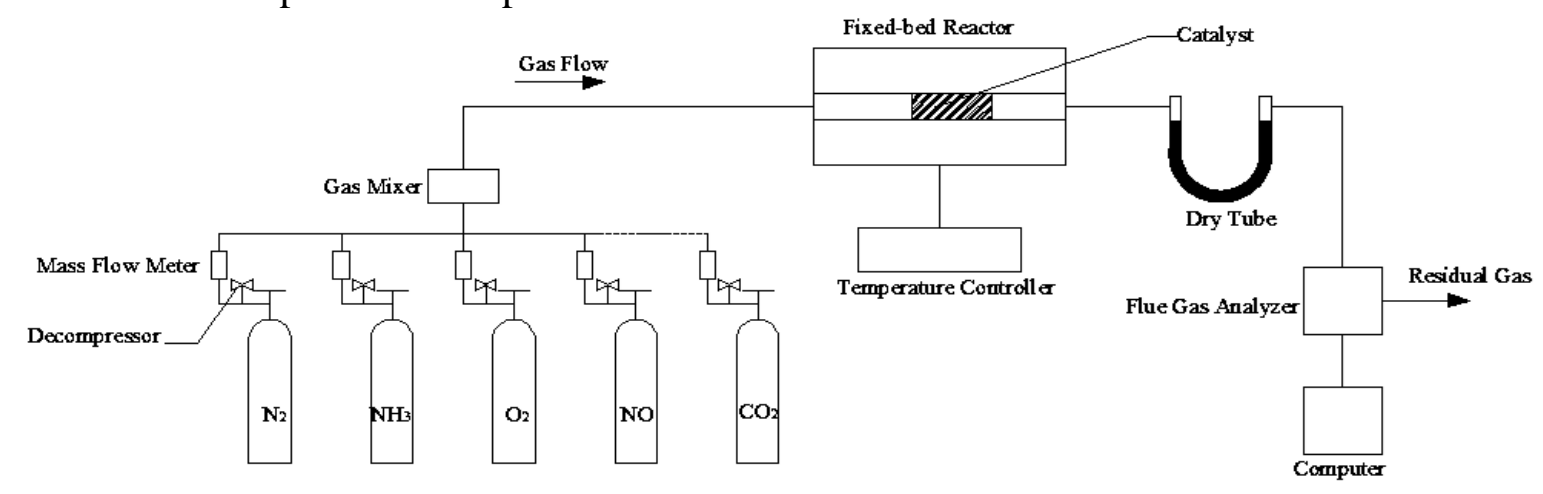

Figure 2. Fixed-bed $\mathrm{NH}_{3}$-SCR experiment system. 
The NO conversion was calculated using the following equation:

$\eta_{\mathrm{NO}}(\%)=\frac{\mathrm{NO}_{\text {inlet }}-\mathrm{NO}_{\text {outlet }}}{\mathrm{NO}_{\text {inlet }}} \times 100 \%$

$\eta_{\mathrm{NO}}$ is the convesion of $\mathrm{NO} \%$; $\mathrm{NO}_{\text {inlet }}$ is the introduced $\mathrm{NO}$ concentration, ppm;

$\mathrm{NO}_{\text {outlet }}$ is the $\mathrm{NO}$ concentration in the outlet of the reactor, ppm.

\section{Results and Discussions}

In $\mathrm{Mn}-\mathrm{Ce} / \mathrm{TiO}_{2}$ catalysts, the molar ratio of $\mathrm{Mn}$ - and $\mathrm{Ti}$ was $0.4: 1$, and the molar ratio of Mnand Ce- was 5:1. The total flow mass of simulated gas was $1400 \mathrm{ml} / \mathrm{min}$; space velocity $4000 \mathrm{~h}^{-1} ; \mathrm{O}_{2}$ content $6 \%$; $\mathrm{NO}$ content $700 \mathrm{ppm}$; $\mathrm{NH}_{3}$ content $700 \mathrm{ppm} . \mathrm{N}_{2} / \mathrm{CO}_{2}$ was presented as balanced gas. in the experiment, the temperature range was between $25^{\circ} \mathrm{C}$ and $300^{\circ} \mathrm{C}$. In changing ammonia-nitrogen oxide ratio experiment, NO content was fixed.

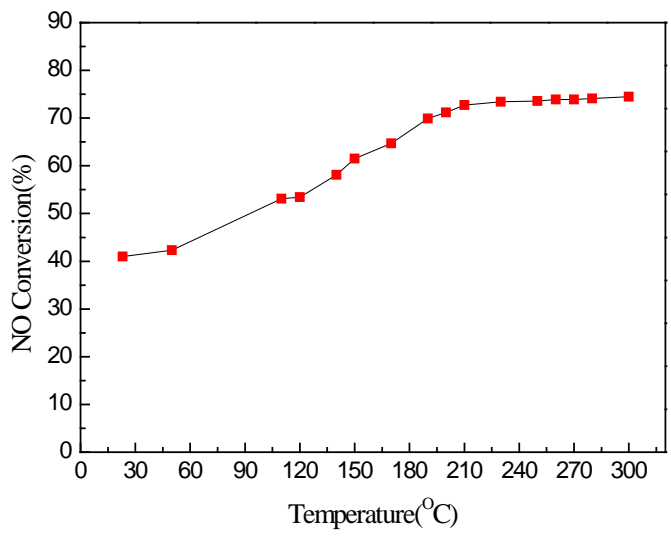

Figure 3. NO conversion under $\mathrm{N}_{2}$ atmosphere

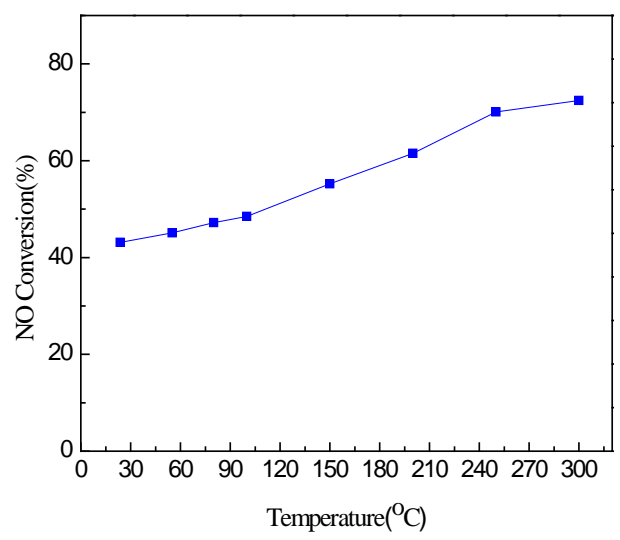

Figure 4. NO conversion under $\mathrm{CO}_{2}$ atmosphere

From Figure 3, under $\mathrm{N}_{2}$ atmosphere, NO conversion shows a trend of increasing with the rise of temperature, and the highest conversion rate is $74.5 \%$ at $300{ }^{\circ} \mathrm{C}$. As shown in Figure 4, under $\mathrm{CO}_{2}$ atmosphere the trend is familiar with $\mathrm{N}_{2}$ atmosphere, and the highest NO conversion rate is $72.4 \%$ at the temperature of $300^{\circ} \mathrm{C}$. The results show that $\mathrm{CO}_{2}$ would inhibit $\mathrm{NO}$ conversion compared with $\mathrm{N}_{2}$.

As shown in Figure 5, with the rising of ammonia-nitrogen oxide ratio, NO conversion rate increases first and then becomes stable at a higer rato. $1.2: 1$ would be a better $\mathrm{NH}_{3}-\mathrm{NO}$ ratio with $\mathrm{Mn}-\mathrm{Ce} / \mathrm{TiO}_{2}$ catalysts in the experiments.

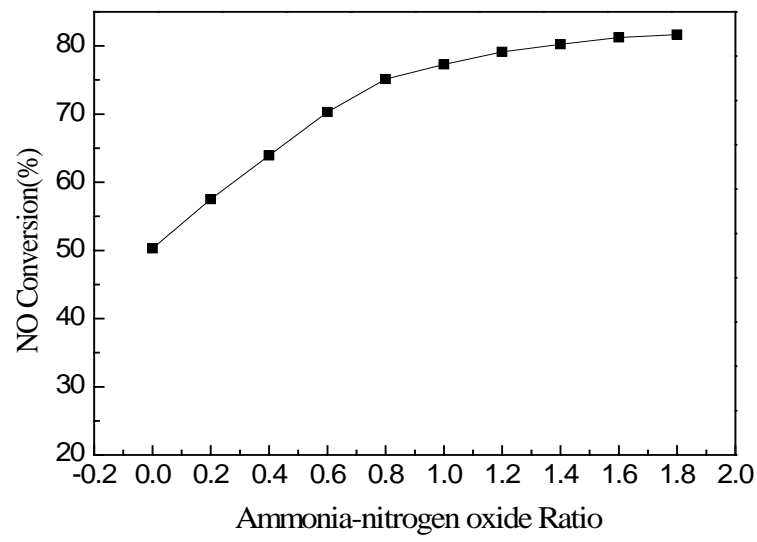

Figure 5. NO conversion changing with ammonia-nitrogen oxide ratio at $250{ }^{\circ} \mathrm{C}$ 


\section{Conclusion}

In this work, $\mathrm{Mn}-\mathrm{Ce} / \mathrm{TiO}_{2}$ catalysts were used for SCR reaction under $\mathrm{CO}_{2}$ and $\mathrm{N}_{2}$ atmosphere respectively. The results showed that $\mathrm{CO}_{2}$ would inhibit $\mathrm{NO}$ conversion and a higher $\mathrm{NH}_{3}-\mathrm{NO}$ ratio could increase NO conversion.

\section{Acknowledgements}

This work was financially supported by the Hebei Applied Basic Research Program of China (Grant No. 13964503D).

\section{References}

[1] Thirupathi Boningari, Padmanabha R. Ettireddy, Arpad Somogyvari, Yi Liu, Alexander Vorontsov, Carl A. McDonald, Panagiotis G. Smirniotis. Influence of elevated surface texture hydrated titania on Ce-dopedMn/ $/ \mathrm{TiO}_{2}$ catalysts for the low-temperature SCR of NOx under oxygen-rich conditions [J]. Journal of Catalysis, 2015325 145-155.

[2] Junlin Xie, De Fang, Feng He, Junfu Chen, Zhengbing Fu, Xiaolin Chen. Performance and mechanism about $\mathrm{MnOx}$ species included in $\mathrm{MnOx} / \mathrm{TiO}_{2}$ catalysts for SCR at low temperature [J]. Catalysis Communications, 201228 77-81.

[3] Lu Qiu, Dandan Pang, Changliang Zhang, Jiaojiao Meng, Rongshu Zhu, Feng Ouyang. In situ IR studies of $\mathrm{Co}$ and $\mathrm{Ce}$ doped $\mathrm{Mn} / \mathrm{TiO}_{2}$ catalyst for low-temperature selective catalytic reductionof $\mathrm{NO}$ with $\mathrm{NH}_{3}$ Catalysis Today, 2013216 76-81.

[4] De Fang, Junlin Xie, Hua Hu, Hu Yang, Feng He, Zhengbing FuIdentification of MnOx species and $\mathrm{Mn}$ valence states in $\mathrm{MnOx} / \mathrm{TiO}_{2}$ catalysts for low temperature SCR [J]. Chemical Engineering Journal, 2015271 23-30.

[5] Guofeng Yu, Yanfei Wei, Ruiben Jin, Hong Zhu, Zhenyu Gu, Lili Pan Study on the DeNOx activity of the Mn-Ce-Co $/ \mathrm{TiO}_{2}$ catalyst at low temperature [J]. Acta Scientiae Circumstantiae, 201232 1743-1749. (In Chinese)

[6] Xiang Gou, Chunfei Wu, Kai Zhang, Guoyou Xu, Meng Si, Yating Wang, Enyu Wang, Liansheng Liu, Jinxiang Wu. Low Temperature Performance of Selective Catalytic Reduction of $\mathrm{NO}$ with $\mathrm{NH}_{3}$ under a Concentrated $\mathrm{CO}_{2}$ Atmosphere [J]. Energies, 20158 12331-2341.

[7] Lixia Wu, Hong Zhu, Huafeng Mao Study on the molding technology of honey corn Mn-Ce $/ \mathrm{TiO}_{2}$ catalysts for low-temperature selective catalytic reduction [J]. Energy and Environment, 2012 5 36-40. (In Chinese) 